\title{
THE ROLE OF LEADERSHIP IN REDUCING ACADEMIC DISHONESTY
}

\author{
Dr. Tim Raynor ${ }^{1 *}$
}

*1Assistant Dean Ernest C. Trefz School of Business University of Bridgeport 230 Park Avenue Bridgeport, CT 06604

*Corresponding Author: -

\begin{abstract}
: -
The article exams the role of school leadership in reducing academic dishonesty. The research reviewed material on educational leadership, academic tegrity/honor codes, faculty enforcement of honor codes, faculty perceptions of honor codes, school climate, school culture, student course evaluations, faculty reactions to student course evaluations and best practices that help reduce academic dishonesty. The role of leadership in combating cheating is extremely important because school leaders can create and promote a positive learning environment that reduces academic dishonesty and improves student learning.
\end{abstract}

Keywords: - role, leadership, reducing, dishonesty 


\section{THE ROLE OF LEADERSHIP IN REDUCING ACADEMIC DISHONESTY}

A popular quote from leadership guru Peter Drucker is "Management is doing things right; leadership is doing the right things." This article focuses on academic integrity in higher education as well as the role of school leadership on reducing academic dishonesty. School leaders can "do the right things" that directly influence both school and student performance by formalizing policies, processes, develop stakeholder relationships and implement strategies that positively impact school climate and culture.

\section{Trends and Issues in Higher education}

Higher Education is in a vibrant, ever changing environment and the study of academic integrity in any form is extremely important and valuable to education as well as society's ability to establish learning communities that are free from academic dishonesty. School leaders are being challenged to address not only academic issues but those issues that are shared with society in general. The study of honor codes, academic integrity, and institutional polices that impact academic dishonesty assist school leaders in the creation of positive learning environments. These positive learning environments benefit our students, schools, workforce and economy. School leaders, faculty, staff, and student perceptions/expectations of the college experience continues to evolve and change. Technology is altering the way that faculty teach, students learn, basic communication, and the ability to catch, monitor and track student academic integrity violations. The constant theme in education and the world is change. School leaders are challenged to stay current in educational and technological trends. They must understand what constitutes an effective academic integrity policy, the importance of creating a positive learning climate, as well as how an effective strategy will help reduce academic dishonesty.

\section{History of Academic Integrity Research}

The first significant research on academic integrity violations (cheating) was Student dishonesty and its control in college conducted in 1964 by Bill Bowers. Bowers surveyed over 5000 college students and found that $75 \%$ of the responding students admitted to one or more academic integrity violations during the previous 12 months. Bowers believed that both the student's social climate as well as institutional climate played important roles in determining the likelihood of academic dishonestly.

6Bowers established that the student's social peer group was extremely influential to the student's behavior. If cheating was an acceptable norm of the group then the likelihood of cheating increased, but if cheating was not an acceptable norm to the group then the likelihood of cheating diminished. There exists a correlation between social factors (peer pressure and acceptable group norms) and student behavior (academic dishonesty).

In 1993 Professors Donald McCabe and Linda Klebe Trevino surveyed over 6000 college students and found that approximately $66 \%$ of the responding students admitted to some level of academic dishonesty. Furthermore McCabe and Trevino identified that academic dishonesty becomes almost an expected behavior or an accepted classroom cultural norm. Students that successfully cheat and receive better grades pressure non-cheaters to adopt the classroom norm of cheating.

McCabe and Trevino researched the significance of institutional policies (Honor Codes/Codes of Conduct) as well as faculty support and participation in the enforcement of these policies. They identified a direct correlation between honor codes/code of conduct, faculty involvement and the level of student academic dishonesty. Honor codes/codes of conduct and faculty involvement help reduce the overall level of academic dishonestly.

Faculty buy-in is very important in addressing academic integrity issues. Early research identified a reluctance by faculty members to take action on suspected academic dishonesty. In an analysis of institutions with and without honor codes, McCabe and Trevino discovered that $60 \%$ of the faculty at institutions without honor codes and $47 \%$ of the faculty at institutions with honor codes said, "they would go to little or very little effort to document an incident" of cheating.

\section{School Leader's role in Academic Integrity}

School leaders are responsible for the overall climate and culture of their institution. Bowers research concluded that school climate and culture was important to maintaining high academic integrity. School leaders need to create an environment that has strong academic integrity polices, training for all stakeholders, and promoted an atmosphere of zero tolerance.

In research published in $1996 \mathrm{McCabe}$ and Trevino concluded that both the student's social climate and (to a lesser extent than Bower) the schools climate and culture played an important role in determining the likelihood of academic dishonestly. They found that "academic dishonesty is most strongly associated with the perceptions of peers' behaviors. It is influenced to a lesser degree by the existence of a code, certainty of being reported, the perceived severity of penalties and, indirectly, by the understanding and acceptance of academic integrity policies."

Shared responsibility for developing positive school climate and culture occurs when the primary stakeholders (school leaders, faculty and staff) join together and agree upon common goals and practices that work towards creating a positive learning environment that promotes and supports academic integrity. Shared school climate and culture is a commitment to academic integrity policies, common practices, effective training, shared beliefs, clearly defined roles, agreed upon hiring practices, group norms for conflict resolution, and established patterns for individual recognition.

McEvoy and Welker (2000) found that when faculty and administration create a positive learning environment the result become positive "protective factors" for many high-risk students. When school leaders develop and communicate effective academic integrity polices, create positive learning environments it will lead to increased achievement for all students. 
Creating a climate that fosters shared ownership and responsibility of academic integrity policy enforcement is the primary responsibility of the school's leadership. Positive school climate and culture benefits all institutional stakeholder and the opposite is also true; a negative climate and culture has a negative impact on learning and student success

What are the right things that school leaders need to do? The Center for Academic Integrity identified seven recommendations that constitute effective academic integrity policies/programs;

1) Have clear academic integrity statements, policies, and procedures that are consistently implemented.

2) Inform and educate the entire community regarding academic integrity policies and procedures.

3) Promulgate and rigorously practice these policies and procedures from the top down, and provide support to those who faithfully follow and uphold them.

4) Have a clear, accessible, and equitable system to adjudicate suspected violations of policy.

5) Develop programs to promote academic integrity among all segments of the campus community. These programs should go beyond repudiation of academic dishonesty and include discussions about the importance of academic integrity and its connection to broader ethical issues and concerns.

6) Be alert to trends in higher education and technology affecting academic integrity on its campus.

7) Regularly assess the effectiveness of its policies and procedures and take steps to improve and rejuvenate them.

Incorporating these seven Academic Integrity recommendations in the school learning community will help the school's leadership to do the right things and combat academic dishonesty. They will have created a school climate and culture that has strong academic integrity polices, training for all stakeholders, and promotes an atmosphere of zero tolerance. 